University of Nebraska - Lincoln

DigitalCommons@University of Nebraska - Lincoln

Publications, Agencies and Staff of the U.S.

Department of Commerce

U.S. Department of Commerce

2012

\title{
Spatial and temporal patterns of vertical distribution for three planktivorous fishes in Lake Washington
}

Thomas P. Quinn

University of Washington, tquinn@u.washington.edu

Christopher J. Sergeant

University of Washington, christopher_sergeant@nps.gov

Anne H. Beaudreau

Northwest Fisheries Science Center, abeaudreau@alaska.edu

David A. Beauchamp

University of Washington, davebea@u.washington.edu

Follow this and additional works at: https://digitalcommons.unl.edu/usdeptcommercepub

Quinn, Thomas P.; Sergeant, Christopher J.; Beaudreau, Anne H.; and Beauchamp, David A., "Spatial and temporal patterns of vertical distribution for three planktivorous fishes in Lake Washington" (2012). Publications, Agencies and Staff of the U.S. Department of Commerce. 428.

https://digitalcommons.unl.edu/usdeptcommercepub/428

This Article is brought to you for free and open access by the U.S. Department of Commerce at DigitalCommons@University of Nebraska - Lincoln. It has been accepted for inclusion in Publications, Agencies and Staff of the U.S. Department of Commerce by an authorized administrator of DigitalCommons@University of Nebraska - Lincoln. 


\title{
Spatial and temporal patterns of vertical distribution for three planktivorous fishes in Lake Washington
}

\author{
Thomas P. Quinn' ${ }^{1}$, Christopher J. Sergeant ${ }^{1, *}$, Anne H. Beaudreau ${ }^{2, \dagger}$, David A. Beauchamp ${ }^{3}$ \\ ${ }^{1}$ School of Aquatic and Fishery Sciences, University of Washington, Box 355020, Seattle, WA 98195-5020, USA \\ ${ }^{2}$ Conservation Biology Division, Northwest Fisheries Science Center, National Marine Fisheries Service, National Oceanic and Atmospheric Administration, 2725 \\ Montlake Boulevard East, Seattle, WA 98112, USA \\ ${ }^{3}$ U.S. Geological Survey, Washington Cooperative Fish and Wildlife Research Unit, School of Aquatic and Fishery Sciences, University of Washington, Box 355020 , \\ Seattle, WA 98195-5020, USA
}

Accepted for publication January 24, 2012

Abstract - We sampled three limnetic fish species: juvenile sockeye salmon (Oncorhynchus nerka), three-spine stickleback (Gasterosteus aculeatus) and longfin smelt (Spirinchus thaleichthys) in Lake Washington to quantify species-specific patterns of diel vertical migration (DVM). Catch-per-unit-effort data analysed from 15 years of midwater trawling documented seasonal and diel differences in vertical distributions for each species. These results were consistent with the hypothesis that the patterns of DVM in Lake Washington were affected by life history, size and morphology. Sockeye salmon showed clear DVM in spring but essentially no DVM in fall, remaining in deep water, whereas three-spine sticklebacks were prevalent at the surface at night in both seasons. In fall, distribution patterns may be explained by differences in thermal performance (e.g., sticklebacks favouring warm water), but the patterns were also consistent with inter-specific differences in predation risk. Younger sockeye salmon and longfin smelt were present in greater proportions higher in the water column during dusk and night periods than older conspecifics. Compared with sockeye salmon, the greater use by three-spine sticklebacks of surface waters throughout the diel cycle during weak thermal stratification in spring was consistent with the hypothesis that sticklebacks' armour reduces predation risk, but use of this warmer, metabolically beneficial stratum may also have promoted growth. This study illustrates variation in the vertical distribution of three sympatric planktivores and offers broader implications for the DVM phenomenon and applied lake ecology.

Key words: diel vertical migration; temperature; predator avoidance; planktivores

\section{Introduction}

Fish need to feed, but foraging is seldom the only factor, and often not the primary factor, affecting their movements and distribution. Conflicts with reproduction, predator avoidance and optimisation of physiological conditions often limit foraging in time and space (Eggers 1978; Coutant 1985, 1987; Clark \& Levy 1988; Appenzeller \& Leggett 1995; Beauchamp et al. 1997). The costs and benefits of foraging in a given area vary among species as a function of life history and among individuals as a function of size or other attributes that make them vulnerable to predation (Levy 1990). The vertical distribution of pelagic fishes can serve as a model for the study of such trade-offs (Clark \& Levy 1988; Scheuerell \& Schindler 2003; Hardiman et al. 2004; Jensen et al. 2006; Gjelland et al. 2009). Zooplankton densities are often higher in the epilimnion, but planktivorous fishes are more vulnerable to visual predators there than in deeper,

Correspondence: T.P. Quinn, School of Aquatic and Fishery Sciences, University of Washington, Box 355020, Seattle, WA 98195-5020, USA. E-mail: tquinn@u.washington.edu

*Present address: National Park Service, 3100 National Park Road, Juneau, AK 99801, USA.

'Present address: School of Fisheries and Ocean Sciences, University of Alaska Fairbanks, 17101 Point Lena Loop Road, Juneau, AK 99801, USA. 


\section{Quinn et al.}

darker waters where zooplankton are less abundant and detectable. In addition to vertical gradients in food availability and predation risk, vertical temperature gradients differentially affect the metabolic rates of predators and prey, further complicating the trade-offs associated with depth (Magnuson et al. 1979; Brandt et al. 1980; Wurtsbaugh \& Neverman 1988). As foraging opportunities and predation risk vary with light levels over the 24-h period, planktivores often show diel vertical migrations (DVM).

Although temperature influences should be secondary to feeding and predation risk during daylight and crepuscular periods, thermal constraints could still be expressed as avoidance of temperatures that were stressful or detrimental to growth when the thermal experience of an individual is averaged over an entire diel cycle. At night, low light levels should inhibit feeding by both planktivorous and piscivorous fishes, so planktivores should occupy depths most beneficial for growth, unencumbered by the need to feed or avoid predators, although clear lakes under either high moon light (Luecke \& Wurtsbaugh 1993) or excessive urban light pollution (Mazur \& Beauchamp 2006; Kitano et al. 2008) may be exceptions to this pattern. Thermal optima vary among species (Coutant 1977; Magnuson et al. 1979), and the different DVM patterns of sympatric coregonids were best explained by differences in thermal ecology (Mehner et al. 2010). Temperatures above and below the optimum limit growth, but the limitation is generally more severe at incrementally warmer than cooler temperatures (Magnuson et al. 1979). The optimal temperature for growth also shifts to cooler temperatures for larger fish and at lower daily energy intake rates (Beauchamp 2009). These features of physiology suggest that DVM patterns should vary seasonally as a lake stratifies and mixes and as prey availability changes, but this seasonal shift was not observed in two coregonid species (Mehner et al. 2007).

Many fishes show DVM, but the patterns may differ among or within species in a given lake (e.g., Piet \& Guruge 1997; Stockwell et al. 2010). Species less vulnerable to predation might be expected to spend more time feeding in profitable epilimnetic waters. The DVM patterns of two coregonids in Lake Superior revealed this pattern, as larger-bodied cisco had a shallower DVM than smaller kiyi (Stockwell et al. 2010). Moreover, fish of the same species may differ in the extent or timing of movement as a function of body size (Levy 1991). For example, a model indicated that older kokanee (nonanadromous sockeye salmon, Oncorhynchus nerka) tend to feed at and migrate to deeper depths than younger smaller fish in reservoirs where abundant large piscivorous lake trout Salvelinus namaycush imposed significant predation risk to all sizes of kokanee (Stockwell \& Johnson
1999; Johnson \& Martinez 2000). The opposite pattern was observed in lakes containing less abundant and smaller piscivores, presenting less predation risk for larger kokanee (Levy 1991).

Diel vertical migration of juvenile sockeye salmon has been closely studied in lakes around the Pacific Rim. These fish enter lakes in spring at a size of ca. $28 \mathrm{~mm}$ after emerging from gravel nests in streams or lake beaches (Quinn 2005), and they feed chiefly on zooplankton in the limnetic zone. They prey on large zooplankton if available (Eggers 1982) and display DVM to balance their foraging needs with predator avoidance (Eggers 1978; Clark \& Levy 1988; Scheuerell \& Schindler 2003). Predator avoidance, prey distribution and temperature all affect the timing of movement and depth distribution (Brett 1971; Clark \& Levy 1988; Levy 1990, 1991; Beauchamp et al. 1997). Because salmonids and their predators are primarily visual foragers, feeding should be confined to daylight and crepuscular periods, and their vertical distribution should be influenced by trade-offs between predation risk and the profitability of feeding at any given depth.

Lake Washington, in Washington State, USA, serves as a model body of water for comparative work on DVM. The lake's thermal regime and zooplankton community are well studied (Arhonditsis et al. 2004; Winder \& Schindler 2004; Hampton et al. 2006a,b; Winder et al. 2009), as is the basic biology of the major planktivores (Chigbu 2000; Beauchamp et al. 2004). The lake has a narrow littoral zone and so the limnetic zone is the primary habitat, dominated by three planktivorous fishes native to the region (juvenile sockeye salmon, three-spine stickleback Gasterosteus aculeatus and longfin smelt Spirinchus thaleichthys), and two native midwater piscivores (cutthroat trout, O. clarki, and northern pikeminnow, Ptychocheilus oregonensis). Densities of Daphnia spp. are significantly higher in the upper $10 \mathrm{~m}$ of the water column than at deeper depths during both thermally stratified and destratified seasons (Edmondson \& Litt 1982); therefore, the DVM patterns of the different planktivores determine their access to zooplankton.

The overall objectives of this study were to (i) quantify variation in planktivore catch-per-uniteffort (CPUE) related to season, diel period and depth and (ii) evaluate whether the diel vertical distributions of planktivores are similar among species and size classes of fish in Lake Washington. We predicted that the armoured species (three-spine stickleback) would exhibit shallower distributions throughout the diel cycle than the un-armoured species (longfin smelt and sockeye salmon) because they may be more willing to accept predation risk. Additionally, we expected to observe shallower distributions throughout the diel cycle for the shorter-lived longfin smelt than the 
longer-lived and potentially more risk-averse, sockeye salmon. With respect to bioenergetic responses, we predicted that all three species should exhibit similar vertical distribution patterns during the cooler, weakly stratified period in April, but that juvenile sockeye salmon would occupy deeper, cooler strata than threespine sticklebacks during the warmer fall stratification period. The range of near-optimal temperatures for juvenile sockeye salmon ( $\geq 90 \%$ maximum growth rate when food is unlimited at $8.0-19.5^{\circ} \mathrm{C}$; Beauchamp 2009) occurs over a cooler and broader range than the warmer, narrower range for three-spine sticklebacks ( $\geq 90 \%$ maximum growth rate when food is unlimited at $19.0-22.5^{\circ} \mathrm{C}$; Lefébure et al. 2011). Thermal optima are unknown longfin smelt, but the species is distributed farther to the south than sockeye salmon (i.e., to the Sacramento River), suggesting that they are more tolerant of warmer water. With respect to size within species, we evaluated the alternative hypotheses that (a) larger fish would forage more cautiously (i.e., move up in the water column later and be deeper overall) because they are already large and so have less to gain energetically, or (b) they would forage less cautiously because their larger size makes them less vulnerable to gape-limited visual predators.

\section{Methods}

\section{Study site}

Lake Washington is $32.2 \mathrm{~km}$ long, averages $2.5 \mathrm{~km}$ wide and has a maximum depth of $66 \mathrm{~m}$. Thermal stratification in the lake begins in March and April, is fully established by late June-early July and persists through October, after which decreasing temperatures and wind destratify the lake through winter. From 1998 to 2010, surface temperatures (0-2 m) in April (spring) averaged $11.0{ }^{\circ} \mathrm{C}$ and bottom temperatures (52-54 m) averaged $7.3{ }^{\circ} \mathrm{C}$ (Fig. 1). October (fall) temperatures averaged $15.4{ }^{\circ} \mathrm{C}$ at the surface and $8.4{ }^{\circ} \mathrm{C}$ at the bottom. Dissolved oxygen levels during our study remained $>5 \mathrm{mg} \cdot \mathrm{l}^{-1}$ throughout the water column, except in some years during August-November when localised benthic levels of $3-5 \mathrm{mg} \cdot \mathrm{l}^{-1}$ were recorded at 50-60 m depths (King County Department of Natural Resources, WA, unpublished data).

The primary crustacean zooplankton species in the lake include the cladoceran Daphnia pulicaria and the copepods Cyclops bicuspidatus, Leptodiaptomus ashlandi and Epischura nevadensis. D. pulicaria typically achieve moderate to high densities (5-35 organisms per l) from mid-May through November but are often below detection levels during winter and early spring (Hampton et al. 2006a,b). Copepod densities during winter and early spring are highly variable among years with either $C$. bicuspidatus or $L$. ashlandi pre-

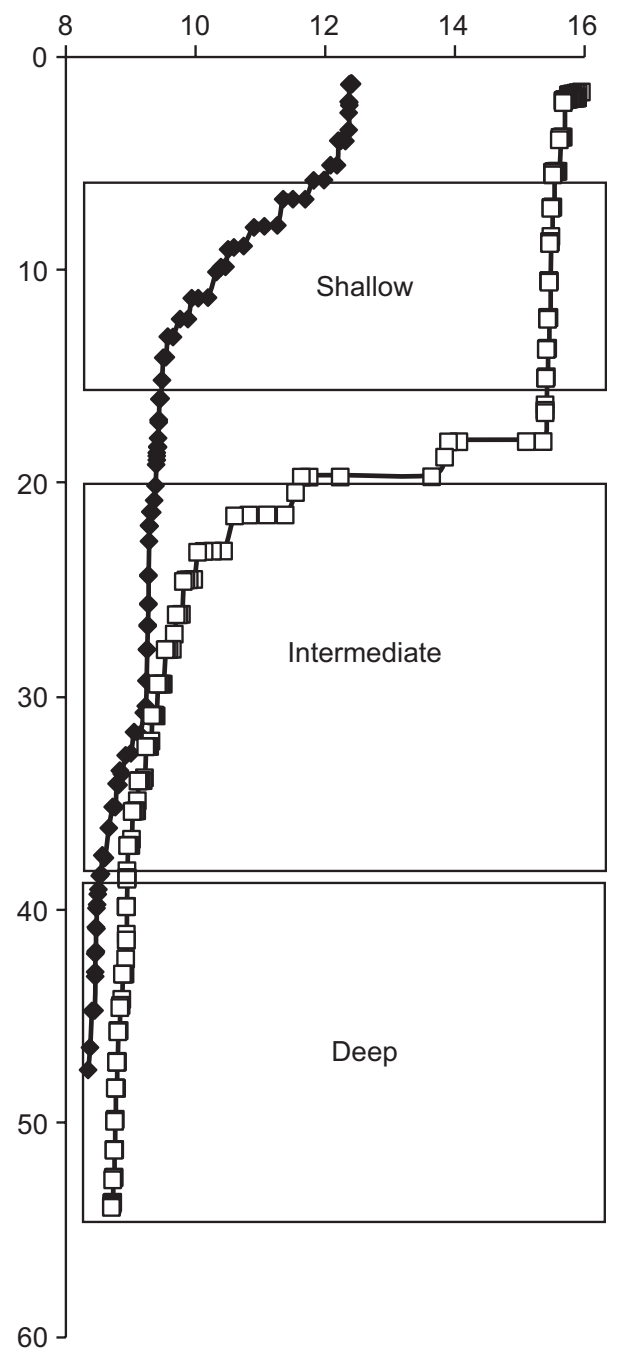

Fig. 1. Spring (April, solid diamonds) and fall (October, open squares) water temperature profiles from the sampling site in Lake Washington in a typical year (2005). Rectangles indicate the modal depth bins where fish were sampled.

dominating in the zooplankton assemblage (430 organisms per 1 for the predominant species; Beauchamp et al. 2004; Winder et al. 2009). In general, the dominant zooplankton (i.e., D. pulicaria) do not vertically migrate and are most dense in the upper $10 \mathrm{~m}$ of the water column and very scarce below $20 \mathrm{~m}$, regardless of season (Edmondson \& Litt 1982).

\section{Fish sampling}

From 1997 to 2011, sampling was conducted in the central basin of Lake Washington, east of Sand Point in water $c a .50 \mathrm{~m}$ deep from 14 to 26 April and 11 to 29 October. These months incorporate several ecological patterns. In April, juvenile sockeye salmon are present in two age classes, age-0 [fry, ca. $30-50 \mathrm{~mm}$ 


\section{Quinn et al.}

fork length (FL)] and age-1 (fish $c a$. 110-130 mm FL that will migrate to sea later that spring; Fig. 2). Longfin smelt are present as age-1 fish (ca. 60-90 mm FL), because the age-2 fish have already spawned in rivers and died by this time of year while young-ofthe-year have not yet recruited to the lake. In October, age-0 sockeye salmon (ca. 100-120 mm FL) are the only age class present, but both age- 0 ( $c a$. 40-60 mm FL) and age-1 (90-110 mm FL; Fig. 2) longfin smelt are present. Catches of limnetic three-spine sticklebacks are low in April because they breed in the littoral zone in late spring, but they are vulnerable to trawling in fall. In addition to these fish community dynamics, April and October present contrasts in thermal regime (cooler and weakly stratified in April; warmer and strongly stratified in October (Fig. 1)) without dramatic differences in overall prey availability. Zooplankton sampling from $25 \mathrm{~m}$ to the surface in the afternoon and at night on each date when fish were sampled revealed mean densities of 17.2 organisms
$\mathrm{L}^{-1}$ in spring and 13.3 in fall. The dominant taxa were D. pulicaria, C. bicuspidatus, Bosmina sp., Epischura sp. and L. ashlandi (T.P. Quinn, unpublished data). D. pulicaria were proportionally less abundant in April, although this varied among years. Independent sampling farther south in the lake revealed similar patterns. The mean depth-stratified densities $( \pm 2 \mathrm{SE})$ of edible crustacean zooplankton during 2000-2007 were the following: $32.6 \pm 20.0 \mathrm{l}^{-1}$ in $0-10 \mathrm{~m}$ and $19.6 \pm 8.9 \mathrm{l}^{-1}$ in $10-20 \mathrm{~m}$ during April (1\% Daphnia) versus $16.4 \pm 3.6 \mathrm{l}^{-1}$ in $0-10 \mathrm{~m}$ and $11.3 \pm 2.1 \mathrm{l}^{-1}$ in 10-20 m during October (31-38\% Daphnia; D.E. Schindler, University of Washington, unpublished data).

Fish were captured using a Kvichak midwater trawl from 1997 to 2011, deployed for $15 \mathrm{~min}$ at three depths from mid-afternoon to night (Table 1). The net, held open by two horizontal metal bars, had a $2.5 \mathrm{~m} \times 2.5 \mathrm{~m}$ cross-section and mesh decreasing from 76- to 2-mm knotless mesh in the cod end. Diel

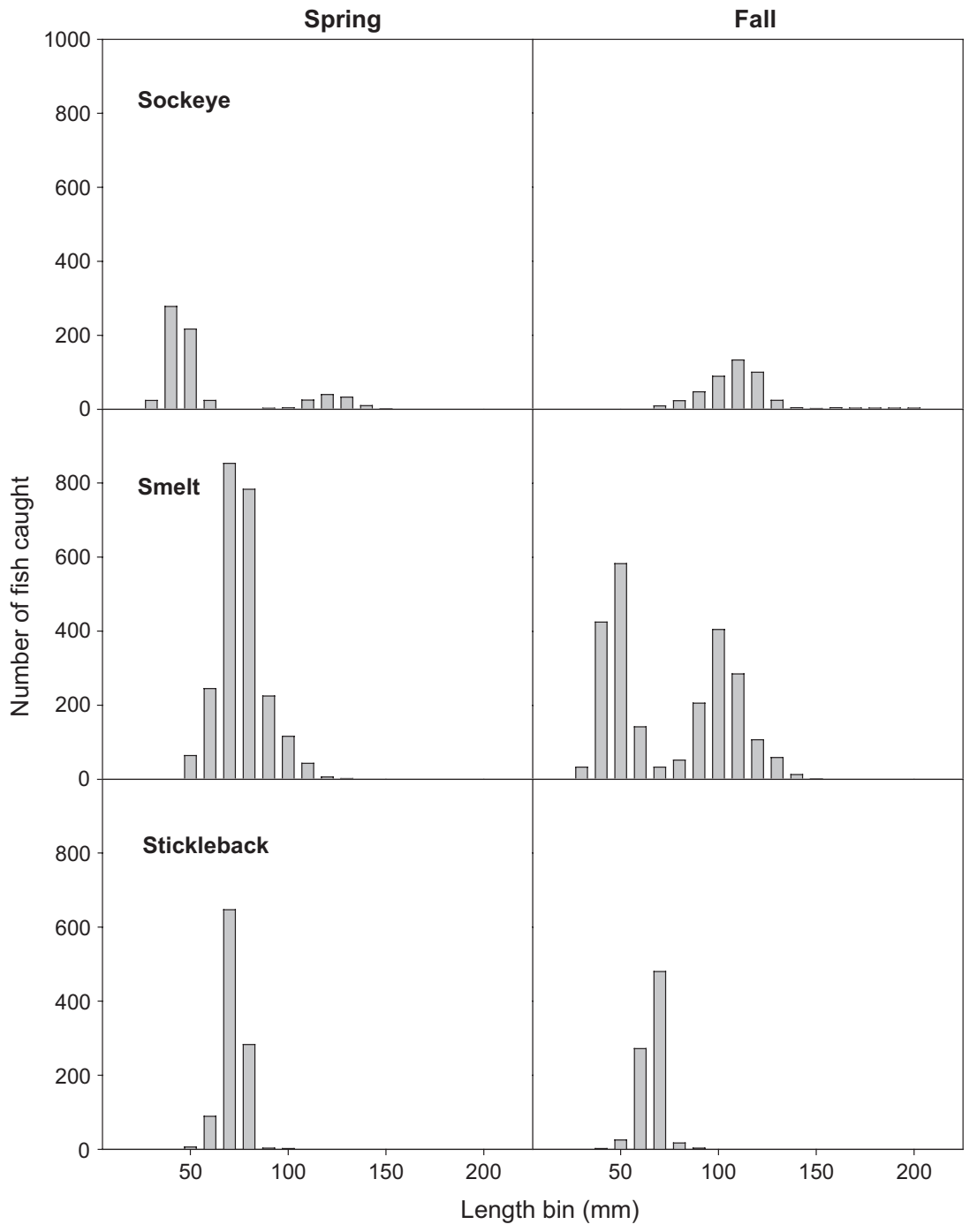

Fig. 2. Length frequency histograms for the three planktivore species sampled in Lake Washington in spring (April) and fall (October), pooling all samples from 1997 to 2011. 
Table 1. Midwater trawl effort from 1997 to 2011, expressed as minutes towed (numbers of tows in parentheses) categorised by season, depth and period of the day.

\begin{tabular}{lllll}
\hline \multirow{2}{*}{ Season } & \multicolumn{4}{l}{ Total trawl minutes (N tows) } \\
\cline { 3 - 5 } & Depth category & Day & Dusk & Night \\
\hline \multirow{2}{*}{ Spring } & Shallow & $679(46)$ & $317(21)$ & $151(10)$ \\
& Intermediate & $668(45)$ & $245(16)$ & $73(5)$ \\
\multirow{3}{*}{ Fall } & Deep & $811(54)$ & $226(15)$ & $105(7)$ \\
& Shallow & $200(14)$ & $75(5)$ & $276(19)$ \\
& Intermediate & $247(17)$ & $46(3)$ & $293(20)$ \\
& Deep & $285(20)$ & $86(6)$ & $237(16)$ \\
\hline
\end{tabular}

periods were categorised as day (before sunset), dusk (sunset to $1.5 \mathrm{~h}$ after sunset) and night ( $>1.5 \mathrm{~h}$ after sunset). Trawl depths were categorised as shallow (6$15 \mathrm{~m})$, intermediate $(20-38 \mathrm{~m})$ and deep (38-54 m; depths shown in Fig. 1). Thermal exposure for fish averaged $9.5-12.0{ }^{\circ} \mathrm{C}$ in spring versus $15.5^{\circ} \mathrm{C}$ in fall at shallow depths, $9.5^{\circ} \mathrm{C}$ in spring versus $10-12{ }^{\circ} \mathrm{C}$ in fall at intermediate depths, and $8.5^{\circ} \mathrm{C}$ in spring versus $9.0{ }^{\circ} \mathrm{C}$ in fall at deep depths. All captured fishes were counted in the field and measured to the nearest millimetre (FL) except in 2 years, when very large catches of age-0 longfin smelt were subsampled for length.

\section{Catch analysis}

To examine the general patterns in planktivore distribution, we calculated the mean number of fish caught per minute trawled across years for discrete depth $\times$ diel $\times$ season sampling cells. Catch data were normalised in this manner to account for slight variation in tow time and differences in effort across sampling cells (Table 1). We used generalised linear models (GLMs) to determine the relative importance of depth, diel period and season in explaining variation in planktivore CPUE for individual species. Model parameter coefficients were used to support speciesspecific patterns in diel vertical distribution. We then examined the CPUE data graphically, to describe differences in diel vertical distribution patterns among species and ages.

Many tows caught no fish; therefore, we used a delta approach to model CPUE because it is appropriate for zero-inflated data (Helser et al. 2004; Maunder \& Punt 2004). CPUE was modelled as a function of environmental variables in a two-stage process. First, the probability of capturing a species (i.e., frequency of occurrence in tows) was estimated using a GLM with a binomial error distribution. Then, the CPUE for nonzero tows was modelled using a negative binomial GLM with a log-link function. Thus, the overall CPUE may be determined as the product of the probability of a nonzero catch and the
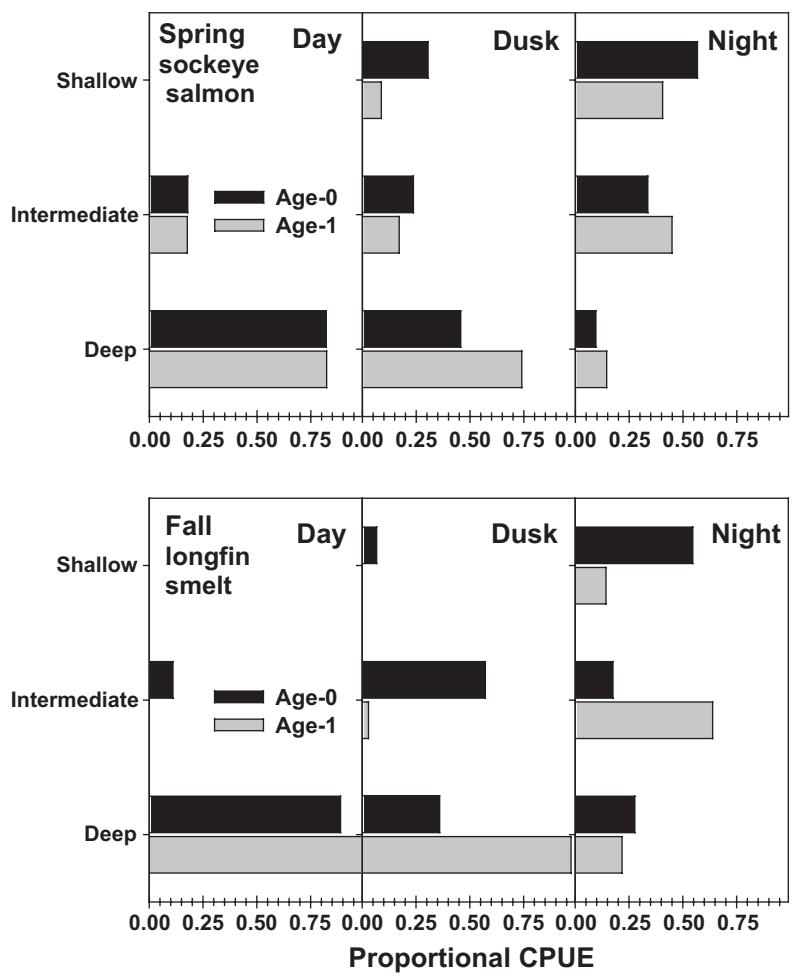

Fig. 3. Diel vertical distributions of age- 0 and age-1 sockeye salmon in the spring (top) and longfin smelt in the fall (bottom). Catch-per-unit-effort (CPUE, $\mathrm{N} \cdot \mathrm{min}^{-1}$ ) was standardised by the total CPUE for each age class $\times$ diel period.

expected CPUE, given that the catch was nonzero. Models were fit separately to data for the three species. Age- 0 and age- 1 fish were combined in the analyses due to small sample sizes for individual age classes; however, we present graphical summaries of agespecific diel vertical distributions (Fig. 3).

Eight GLMs were evaluated for each species, including the null model (intercept only) and all possible combinations of three discrete predictor variables: depth (shallow, intermediate and deep); diel period (day, dusk and night); and season (fall and spring). Models provided reasonably good fits to the data; estimated dispersion parameters ranged from 0.60 to 1.43 , indicating little evidence of over- or under-dispersion (Helser et al. 2004). Additionally, diagnostic plots of deviance residuals versus fitted values from the full models showed constant variance, and half-normal plots of the residuals showed no outliers (Faraway 2006).

For each stage of the analytical process described earlier, we compared the eight candidate models using Akaike's information criteria, bias-corrected for small sample size (AICc), which balances model complexity (number of estimated parameters) with the goodness of fit, as determined by likelihood (Burnham \& Anderson 2002). The $\triangle \mathrm{AICc}$ was calculated for each model as its AICc minus the lowest AICc across all 


\section{Quinn et al.}

models; by convention, models with $\triangle \mathrm{AICc}$ within two of the minimum AICc are classified as performing equivalently to the best approximating model (Burnham $\&$ Anderson 2002). We calculated the Akaike weight $\left(w_{i}\right)$ for each model, interpreted as the weight of evidence (probability) that model $i$ is the best approximating model from among the set of candidate models (Johnson \& Omland 2004). As $w_{i}$ approaches one, the weight of evidence in favour of model $i$ increases (Burnham \& Anderson 2002). The relative importance of each predictor variable $j\left(w_{j}\right)$ was estimated by summing $w_{i}$ across all models in the set that included variable $j$; the closer $w_{j}$ is to 1 , the more important the variable in predicting the response across all models (Burnham \& Anderson 2002).

\section{Results}

Longfin smelt were the most abundant species caught by midwater trawling during spring and fall sampling periods (71.7\% of all fish caught), followed by threespine stickleback (18.6\%) and sockeye salmon (9.7\%). Season, depth and diel period were important predictors of frequency of occurrence and density (nonzero CPUE) for all three species, based on their inclusion in the set of best approximating models (Table 2). For all species, observed spatial-temporal patterns in CPUE (Figs 4 and 5) were supported by coefficient values from best-fit models; coefficient estimates from the full models indicate the magnitude and direction of the effect of each parameter on planktivore CPUE (Table 3). For example, slope coefficients estimated from the full model for sockeye (Table 3) increased from day to night periods; this mirrors the graphical trend in sockeye CPUE (Fig. 4). Qualitative differences in patterns of age-specific CPUE were apparent in spring for sockeye salmon and in fall for longfin smelt. Generally, younger fish were caught in larger proportions higher in the water column during dusk and night periods than older conspecifics (Fig. 3).

Juvenile sockeye salmon demonstrated a seasonal shift in diel vertical distribution patterns. During spring, CPUE was highest in deep water during the day, intermediate depths at dusk and shallow depths at night (Fig. 4), whereas in the fall the highest CPUE was in deep water across all diel periods (Fig. 5). In both seasons, the frequency of occurrence and density increased dramatically from afternoon to dusk and night. Variation in sockeye salmon occurrence was related strongly to season, depth and diel period $\left(w_{j}=1.0\right)$; however, diel period and depth were more important than season in dictating the density of sockeye (Table 4). Sockeye salmon were encountered less frequently in fall surveys than in the spring but were captured in similar densities (nonzero CPUE) across seasons (Table 3 ).
Table 2. Diagnostic statistics for generalised linear models describing the relationships between catch-per-unit-effort (CPUE) and environmental factors. CPUE was modelled using a two-stage process, first estimating the probability of capturing a species (a) and then modelling the CPUE given that the species was caught (b). AICc is Akaike's information criteria biascorrected for small sample size, $\triangle \mathrm{AICC}$ is the AICc for each model minus the lowest AICc from all possible models, and $w_{i}$ is the model Akaike weight.

\begin{tabular}{|c|c|c|c|c|c|c|}
\hline & \multicolumn{3}{|c|}{$\begin{array}{l}\text { (a) Frequency of } \\
\text { occurrence }\end{array}$} & \multicolumn{3}{|c|}{$\begin{array}{l}\text { (b) CPUE, nonzero } \\
\text { tows }\end{array}$} \\
\hline & AICc & $\triangle \mathrm{AlCc}$ & $w_{i}$ & AICc & $\triangle \mathrm{AICC}$ & $w_{i}$ \\
\hline \multicolumn{7}{|l|}{ Sockeye salmon } \\
\hline \multicolumn{7}{|l|}{ Model parameters } \\
\hline $\begin{array}{l}\text { Depth + Diel + Season } \\
\text { (full model) }\end{array}$ & 332.0 & 0.0 & 1.00 & 821.9 & 2.2 & 0.22 \\
\hline Depth + Diel & 367.1 & 35.0 & 0.00 & 819.7 & 0.0 & 0.67 \\
\hline Depth + Season & 423.8 & 91.7 & 0.00 & 838.2 & 18.6 & 0.00 \\
\hline Depth & 431.5 & 99.5 & 0.00 & 849.2 & 29.5 & 0.00 \\
\hline Diel + Season & 380.6 & 48.6 & 0.00 & 825.4 & 5.7 & 0.04 \\
\hline Diel & 406.4 & 74.4 & 0.00 & 824.1 & 4.4 & 0.07 \\
\hline Season & 449.0 & 116.9 & 0.00 & 844.9 & 25.2 & 0.00 \\
\hline Intercept (null model) & 455.2 & 123.2 & 0.00 & 853.1 & 33.4 & 0.00 \\
\hline \multicolumn{7}{|l|}{ Longfin smelt } \\
\hline \multicolumn{7}{|l|}{ Model parameters } \\
\hline $\begin{array}{l}\text { Depth + Diel + Season } \\
\text { (Full model) }\end{array}$ & 303.0 & 0.0 & 0.98 & 1821.1 & 0.0 & 0.47 \\
\hline Depth + Diel & 310.9 & 8.0 & 0.02 & 1834.3 & 13.3 & 0.00 \\
\hline Depth + Season & 404.6 & 101.6 & 0.00 & 1825.1 & 4.1 & 0.06 \\
\hline Depth & 431.2 & 128.2 & 0.00 & 1854.9 & 33.9 & 0.00 \\
\hline Diel + Season & 349.3 & 46.3 & 0.00 & 1821.2 & 0.1 & 0.44 \\
\hline Diel & 357.2 & 54.2 & 0.00 & 1832.3 & 11.3 & 0.00 \\
\hline Season & 428.4 & 125.4 & 0.00 & 1826.3 & 5.3 & 0.03 \\
\hline Intercept (Null model) & 453.8 & 150.8 & 0.00 & 1855.4 & 34.3 & 0.00 \\
\hline \multicolumn{7}{|l|}{ Three-spine stickleback } \\
\hline \multicolumn{7}{|l|}{ Model parameters } \\
\hline $\begin{array}{l}\text { Depth + Diel + Season } \\
\text { (Full model) }\end{array}$ & 416.3 & 0.9 & 0.29 & 1028.0 & 2.0 & 0.26 \\
\hline Depth + Diel & 415.4 & 0.0 & 0.46 & 1026.0 & 0.0 & 0.70 \\
\hline Depth + Season & 464.6 & 49.3 & 0.00 & 1032.2 & 6.2 & 0.03 \\
\hline Depth & 464.1 & 48.7 & 0.00 & 1034.6 & 8.6 & 0.01 \\
\hline Diel + Season & 418.6 & 3.2 & 0.09 & 1062.6 & 36.6 & 0.00 \\
\hline Diel & 417.5 & 2.1 & 0.16 & 1063.3 & 37.3 & 0.00 \\
\hline Season & 463.6 & 48.3 & 0.00 & 1074.5 & 48.5 & 0.00 \\
\hline Intercept (null model) & 463.1 & 47.7 & 0.00 & 1076.6 & 50.6 & 0.00 \\
\hline
\end{tabular}

Variation in longfin smelt occurrence and density were related strongly to season and diel period $\left(w_{j}=0.91-1.00\right)$ and, to a lesser extent, depth $\left(w_{j}=0.53-1.0 ;\right.$ Table 4$)$. Longfin smelt demonstrated distinct DVM patterns during both spring and fall, with CPUE increasing in intermediate and shallow depths from day to night periods (Figs 4 and 5). Smelt were encountered more frequently and captured in higher densities in fall than in spring (Table 3).

Depth and diel period were more important than season in dictating the occurrence and density of threespine stickleback (Table 4). The highest densities of three-spine stickleback occurred in shallow depths during all diel periods in the spring (Fig. 4) and at night in the fall, but they were captured in very low densities at all depths during daylight and dusk in the fall (Fig. 5). 
Spatial and temporal patterns of vertical distribution

Fig. 4. Spring (April) depth distribution of sockeye salmon, longfin smelt and threespine stickleback during day, dusk and night periods. Mean catch-per-unit-effort (CPUE, $\left.\mathrm{N} \cdot \mathrm{min}^{-1}\right)$ is shown for all sampling years combined (1997-2011).
Fig. 5. Fall (October) depth distribution of sockeye salmon, longfin smelt and threespine stickleback during day, dusk and night periods. Mean catch-per-unit-effort (CPUE, $\mathrm{N} \cdot \mathrm{min}^{-1}$ ) is shown for all sampling years combined (1997-2011).
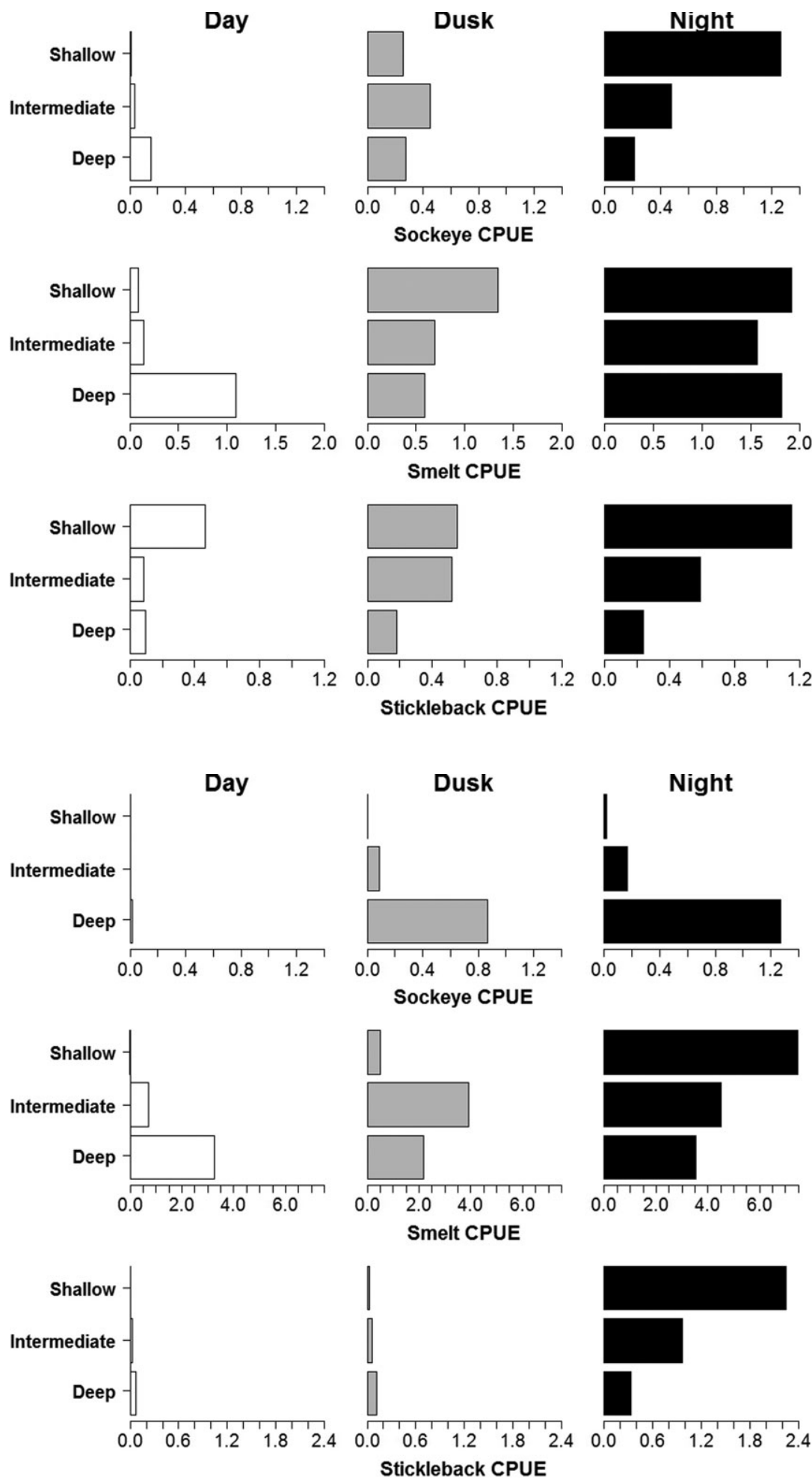

In summary, CPUE data provided evidence of DVM from deep water during the day to shallow water at night for all planktivores, but the strength of this distributional pattern and consistency between seasons varied among species. Sockeye salmon demonstrated a strong DVM during the spring, but remained at highest densities in deep water across diel periods during the fall. Longfin smelt exhibited DVM in both seasons and were more evenly distributed throughout the water column at night than the other species. Three-spine stickleback also showed increasing densities in shallow waters from day to night periods during both seasons, but were generally more abundant in shallow water across all diel periods. 
Quinn et al.

Table 3. Parameter estimates from generalised linear models describing the (a) frequency of occurrence and (b) nonzero catch-per-unit-effort (CPUE) for three species. Coefficients (SE) are shown for the full model (Diel + Depth + Season).

\begin{tabular}{lrr}
\hline & $\begin{array}{l}\text { (a) Frequency of } \\
\text { occurrence }\end{array}$ & $\begin{array}{l}\text { (b) CPUE, } \\
\text { nonzero tows }\end{array}$ \\
\hline Sockeye salmon (full model) & & \\
Intercept & $-1.05(0.41)$ & $-1.04(0.21)$ \\
Season: Oct & $-2.16(0.41)$ & $0.01(0.24)$ \\
Diel: Day & $-2.62(0.40)$ & $-0.93(0.24)$ \\
Diel: Night & $0.69(0.46)$ & $0.47(0.23)$ \\
Depth: Shallow & $-1.54(0.38)$ & $0.44(0.27)$ \\
Depth: Deep & $0.99(0.33)$ & $0.64(0.21)$ \\
Longfin smelt (full model) & & \\
Intercept & $-1.02(0.44)$ & $-0.22(0.23)$ \\
Season: Oct & $1.05(0.34)$ & $0.83(0.20)$ \\
Diel: Day & $-2.77(0.43)$ & $0.21(0.24)$ \\
Diel: Night & $0.93(0.65)$ & $0.74(0.26)$ \\
Depth: Shallow & $-0.99(0.38)$ & $0.52(0.25)$ \\
Depth: Deep & $1.52(0.36)$ & $0.33(0.22)$ \\
Three-spine stickleback (Full model) & \\
Intercept & $-2.28(0.32)$ & $-0.64(0.26)$ \\
Season: Oct & $-0.30(0.28)$ & $-0.14(0.25)$ \\
Diel: Day & $-1.38(0.30)$ & $-0.04(0.27)$ \\
Diel: Night & $0.69(0.39)$ & $0.86(0.30)$ \\
Depth: Shallow & $-0.11(0.30)$ & $0.84(0.26)$ \\
Depth: Deep & $0.57(0.30)$ & $-0.85(0.26)$ \\
\hline
\end{tabular}

Table 4. Parameter Akaike weights $\left(w_{j}\right)$ calculated from all candidate generalised linear models, describing the relationships between catch-perunit-effort (CPUE) in biannual trawl surveys and environmental factors. CPUE was modelled using a two-stage process, first estimating the probability of capturing a species (a) and then modelling the CPUE given that the species was caught (b).

\begin{tabular}{|c|c|c|}
\hline & $\begin{array}{l}\text { (a) Frequency of } \\
\text { occurrence }\end{array}$ & $\begin{array}{l}\text { (b) CPUE, nonzero } \\
\text { tows }\end{array}$ \\
\hline Parameter & $w_{j}$ & $w_{j}$ \\
\hline \multicolumn{3}{|c|}{ Sockeye salmon } \\
\hline Depth & 1.00 & 0.89 \\
\hline Diel & 1.00 & 1.00 \\
\hline Season & 1.00 & 0.26 \\
\hline \multicolumn{3}{|c|}{ Longfin smelt } \\
\hline Depth & 1.00 & 0.53 \\
\hline Diel & 1.00 & 0.91 \\
\hline Season & 0.98 & 1.00 \\
\hline \multicolumn{3}{|c|}{ Three-spine stickleback } \\
\hline Depth & 0.75 & 1.00 \\
\hline Diel & 1.00 & 0.96 \\
\hline Season & 0.38 & 0.29 \\
\hline
\end{tabular}

\section{Discussion}

Midwater trawl data from Lake Washington demonstrated species-specific variation in the vertical distribution patterns of three planktivores across season and diel periods. The three species differed from each other, and in general, the hypotheses proposed for species-specific variation in DVM were supported. The DVM indicated by the sockeye salmon data was consistent with that of prior work on Lake Washington (Eggers 1978) and elsewhere (Levy 1987; Scheuerell
\& Schindler 2003) on this species. Sockeye salmon reside in lakes for the first year or two of their lives, followed by migration to sea for the majority of their growth prior to return for spawning. In general, they grow slowly, as indicated by their smaller size at age when leaving freshwater compared with coho salmon, O. kisutch, a stream-rearing species, and smaller size for their age at sea than other Pacific salmon (Quinn 2005). In Lake Washington, age-0 sockeye salmon feed and grow much slower during their first months in the lake (Beauchamp et al. 2004) than sympatric lake-rearing Chinook salmon (Koehler et al. 2006). Where sympatric with pink salmon, O. gorbuscha, in lakes, sockeye salmon grow slower as well (Robins et al. 2005), and they seem to be generally unaggressive and risk-averse (Hoar 1954; Hutchison \& Iwata 1997). Their nocturnal use of surface waters during spring was advantageous for growth, given the size and feeding rates exhibited by age- 0 sockeye and to a lesser degree for the age-1 smolts (Beauchamp et al. 2004). In contrast, their strong avoidance of shallow strata during fall, when growth was insensitive to the range of temperatures available in deep $\left(\sim 9^{\circ} \mathrm{C}\right)$ through shallow $\left(\mathrm{ca} .15-16{ }^{\circ} \mathrm{C}\right)$ depths (Beauchamp 2009), was more consistent with predator avoidance.

There is less information on DVM by three-spine sticklebacks than by sockeye salmon, but DVM was reported in the Baltic Sea by Jurvelius et al. (1996) and Iliamna Lake, Alaska, by Quinn et al. (2012). In Alaska, significant numbers of sticklebacks were caught at the surface during the day, and their vertical shift in distribution was relatively subtle. In contrast, daytime catch rates of sockeye salmon at that lake were negligible compared with night-time catches (T.P. Quinn, unpublished data). Compared with sockeye salmon, three-spine sticklebacks are armoured (though still subject to predation from birds and fishes; Kitano et al. 2008), have a 1-year lifespan in Lake Washington (Eggers et al. 1978), and warmer optimal temperature for growth (Lefébure et al. 2011). During both spring and fall, the shallow stratum offered higher growth benefits for three-spine sticklebacks than either the intermediate or deep strata. These features likely all contributed to their greater proximity to the surface. Longfin smelt appeared to be intermediate between sockeye salmon and three-spine sticklebacks in their use of the epilimnion and extent of DVM. Like sockeye salmon, they lack defensive structures and are readily consumed by cutthroat trout in the lake (Beauchamp et al. 1992; Nowak et al. 2004), but their lifespan is much shorter, typically maturing at age-2 (Moulton 1974; Chigbu 2000).

Our age-specific samples of sockeye salmon in spring and longfin smelt in fall were insufficient for the rigorous statistical comparisons needed to test the two hypotheses concerning size effects on DVM, so 
these results should be interpreted cautiously. However, the general patterns (Fig. 3) indicated greater proximity to the surface among the young-ofthe-year, especially in longfin smelt. These fish would be more vulnerable to predation on the basis of size than the yearlings, and the use of the surface waters suggests that foraging to achieve growth was more important than predation risk. However, two features of the biology of smelt complicate this interpretation. First, the young-of-the-year are nearly transparent and so may be less vulnerable to visual predators than might be expected based on the size alone. In addition, the larger smelt feed more heavily on Neomysis than do smaller smelt (Chigbu and Sibley 1998), and Neomysis are closely associated with the bottom during the day, whereas zooplankton are primarily in the epilimnion. This difference in the locations of focal prey may also affect the vertical distributions of the age groups. Recently, Busch \& Mehner (2012) reported earlier and more rapid ascent at dusk by smaller coregonids compared to larger ones, so the size-specific DVM patterns we saw may be genuine but further sampling is needed.

For all three species across all depths and seasons, there was a large disparity in CPUE among diel periods (lowest during daylight, intermediate at dusk and highest at night). Although light-mediated gear avoidance likely contributed to this disparity, this pattern was also observed in unbiased seasonal and diel hydroacoustic surveys (Beauchamp et al. 1999; Mazur \& Beauchamp 2006). This disparity could be explained by schooling or a strong benthic association during daylight followed by partial or full dispersal into the water column at dusk and night. Our net was not designed to sample on the bottom, so close proximity to the bottom would greatly reduce vulnerability to the gear. Daylight schooling can be difficult to detect, much less quantify, by either small midwater trawls or narrow beam hydroacoustics. Nonetheless, occasional schools have been detected in the upper $10 \mathrm{~m}$ of the lake during hydroacoustic surveys in October (Mazur 2004; D.A. Beauchamp, unpublished data), and a single catch of nearly 17,000 three-spine sticklebacks was encountered when fishing at $15 \mathrm{~m}$ during daylight in October 2001 as well (Overman et al. 2006).

The seasonal and diel vertical distribution patterns of the three planktivores may reflect trade-offs between antipredation behaviour and bioenergetic benefits from behavioural thermoregulation. The low densities of nonschooling planktivores in the upper water column during daylight in both seasons, except for the armoured three-spine sticklebacks in spring, suggested that predator avoidance was a high priority during high-light periods. The depth distribution patterns during dusk were often intermediate between day and night periods and could reflect either a critical feeding period during an antipredation window (e.g., Eggers 1978; Clark \& Levy 1988; Scheuerell \& Schindler 2003) or simply a transition from daylight to nocturnal distributions. Strong crepuscular feeding peaks were reported for longfin smelt (Dryfoos 1965) and juvenile sockeye salmon (Doble \& Eggers 1978) in Lake Washington during the 1960s and early 1970s, before the emergence of Daphnia as the predominant zooplankter in the mid-1970s.

The depth distributions at night likely reflected thermoregulation, because darkness should minimise predation risk and inhibit feeding by the planktivores. The juvenile sockeye salmon moved into the epilimnion at night in spring, where the warmer temperatures offered a bioenergetic growth benefit. However, when the thermal benefit was neutral in fall, they remained in deep water at night. In contrast, the epilimnetic temperatures during both spring and fall were beneficial for growth of three-spine stickleback, and presumably for longfin smelt, and the highest catches of both species were in shallow depths at night during both seasons. Although little is known about the thermal preferences of longfin smelt, their optimal temperature is likely higher than for sockeye salmon, based on the much more southerly range of anadromous populations (Scott \& Crossman 1973) and their generally shallower distribution in stratified lakes (Enzenhofer \& Hume 1989; Chigbu et al. 1998). During peak thermal stratification in July-September, the $18-23{ }^{\circ} \mathrm{C}$ average epilimnetic temperatures in Lake Washington (Arhonditsis et al. 2004) would markedly reduce the growth of sockeye salmon, but optimise the growth of three-spine stickleback and possibly of longfin smelt.

The seasonal differences in DVM among species have implications for their vulnerability visually feeding limnetic predators. Using telemetry data on cutthroat trout (Nowak \& Quinn 2002) and hydroacoustic data on nonschooling planktivores, a visual detection foraging model predicted that in spring, most predator-prey encounters would occur in the upper $12 \mathrm{~m}$ during all diel periods but rates were highest at dusk in the upper $6 \mathrm{~m}$ (Mazur \& Beauchamp 2006). In fall, most predator-prey encounters would occur in the upper $21 \mathrm{~m}$ of the water column during all diel periods, with slightly higher maximum encounter rates in the upper $6 \mathrm{~m}$ at night (Mazur \& Beauchamp 2006). These predicted encounter rates suggest that the planktivores were only vulnerable to predation in the shallow stratum. Thus in April, a larger fraction of the three-spine stickleback population was vulnerable to encounters with predators than in fall, followed by longfin smelt, and then sockeye salmon. In October, these species displayed the same ordering in terms of predicted encounter rates with predators, but sockeye 


\section{Quinn et al.}

salmon were much less vulnerable than in the spring. Indeed, during 1995-2000, juvenile sockeye salmon represented larger fractions of the limnetic cutthroat trout diets in spring than in the fall, whereas longfin smelt contributed less to trout diets in spring than in fall, and sticklebacks contributed considerably less during any season for data spanning 1984-2000 (Beauchamp et al. 1992; Nowak et al. 2004). Following the recent fivefold increase in three-spine sticklebacks (Overman \& Beauchamp 2006; Overman et al. 2006), they represented larger fractions of cutthroat trout diets (but low prey electivity indices) during spring and fall, while similar patterns in seasonal contributions by the other species persisted (D.A. Beauchamp, unpublished data).

In addition to the patterns documented by this study for the three planktivore species in Lake Washington, it offers broader implications for the DVM phenomenon and applied lake ecology. As noted by Piet \& Guruge (1997), vertical distribution and DVM affect many aspects of community ecology in lakes, including the influences of non-native species. Assessment of these ecological interactions is greatly complicated by the variation in species-specific DVM patterns with season and size, and changing community composition at different trophic levels as species invade lakes and cascading effects occur. Lake Washington has had a particularly interesting and well-studied history of sequential effects of natural and human-related processes (Edmondson 1994; Winder et al. 2009), but it is certainly not unique. Modelling efforts directed at the conservation of species at risk and control of unwanted invasive species may hinge in part on complex trophic interactions affected by DVM patterns.

\section{Acknowledgements}

We thank the vessel crews for sampling assistance and especially Kurt Dobszinsky and the F/V Chasina. We are grateful to Rachel Hovel for sharing unpublished experimental data on thermal bioenergetics of three-spine sticklebacks. Funding was provided by the instructional programme at the University of Washington's School of Aquatic and Fishery Sciences, and we thank the many students and teaching assistants for their help. Additional funding was provided by the Worthington Endowed Professorship. The Washington Cooperative Fish and Wildlife Unit is jointly supported by the U.S. Geological Survey; University of Washington, Washington Departments of Ecology, Fish and Wildlife, and Natural Resources; U.S. Fish and Wildlife Service; and the Wildlife Institute. The use of trade, product or firm names in this publication is for descriptive purposes only and does not imply endorsement by the U.S. Government.

\section{References}

Appenzeller, A.R. \& Leggett, W.C. 1995. An evaluation of light-mediated vertical migration of fish based on hydroa- coustic analysis of the diel vertical movements of rainbow smelt (Osmerus mordax). Canadian Journal of Fisheries and Aquatic Sciences 52: 504-511.

Arhonditsis, G.B., Brett, M.T., DeGasperi, C.L. \& Schindler, D.E. 2004. Effects of climatic variability on the thermal properties of Lake Washington. Limnology and Oceanography 49: 256-270.

Beauchamp, D.A. 2009. Bioenergetic ontogeny: linking climate and mass-specific feeding to life-cycle growth and survival of salmon. American Fisheries Society Symposium 70: 53-72.

Beauchamp, D.A., Vecht, S.A. \& Thomas, G.L. 1992. Temporal, spatial, and size-related foraging of wild cutthroat trout in Lake Washington. Northwest Science 66: 149-159.

Beauchamp, D.A., Luecke, C., Wurtsbaugh, W.A., Gross, H.G., Budy, P.E., Spaulding, S., Dillenger, R. \& Gubala, C.P. 1997. Hydroacoustic assessment of abundance and diel distribution of sockeye salmon and kokanee in the Sawtooth Valley Lakes, Idaho. North American Journal of Fisheries Management 17: 253-267.

Beauchamp, D.A., Baldwin, C.M., Vogel, J.L. \& Gubala, C.P. 1999. Estimating diel, depth-specific foraging opportunities with a visual encounter rate model for pelagic piscivores. Canadian Journal of Fisheries and Aquatic Sciences 56: 128139.

Beauchamp, D.A., Sergeant, C.J., Mazur, M.M., Scheuerell, J.M., Schindler, D.E., Scheuerell, M.D., Fresh, K.L., Seiler, D.E. \& Quinn, T.P. 2004. Spatial-temporal dynamics of early feeding demand and food supply by sockeye salmon fry in Lake Washington. Transactions of the American Fisheries Society 133: 1014-1032.

Brandt, S.B., Magnuson, J.J. \& Crowder, L.B. 1980. Thermal habitat partitioning by fishes in Lake Michigan. Canadian Journal of Fisheries and Aquatic Sciences 37: 1557-1564.

Brett, J.R. 1971. Energetic response of salmon to temperature. A study of some thermal relations in the physiology and freshwater ecology of sockeye salmon (Oncorhynchus nerka). American Zoologist 11: 99-113.

Burnham, K.P. \& Anderson, D.R. 2002. Model selection and multimodel inference: a practical information-theoretic approach. New York: Springer Science+Business Media, Inc.

Busch, S. \& Mehner, T. 2012. Size-dependent patterns of diel vertical migration: smaller fish may benefit from faster ascent. Behavioral Ecology 23: 210-217.

Chigbu, P. 2000. Population biology of longfin smelt and aspects of the ecology of other major planktivorous fishes in Lake Washington. Journal of Freshwater Ecology 15: 543557.

Chigbu, P. \& Sibley, T.H. 1998. Predation by longfin smelt (Spirinchus thaleichthys) on the mysid Neomysis mercedis in Lake Washington. Freshwater Biology 40: 295-304.

Chigbu, P., Sibley, T.H. \& Beauchamp, D.A. 1998. Abundance and distribution of (Neomysis mercedis) and a major predator, longfin smelt (Spirinchus thaleichthys) in Lake Washington. Hydrobiologia 386: 167-182.

Clark, C.W. \& Levy, D.A. 1988. Diel vertical migrations by juvenile sockeye salmon and the antipredation window. American Naturalist 131: 271-290.

Coutant, C.C. 1977. Compilation of temperature preference data. Journal of the Fisheries Research Board of Canada 34: 739-745. 
Coutant, C.C. 1985. Striped bass, temperature, and dissolved oxygen: a speculative hypothesis for environmental risk. Transactions of the American Fisheries Society 114: 31-61.

Coutant, C.C. 1987. Poor reproductive success of striped bass from a reservoir with reduced summer habitat. Transactions of the American Fisheries Society 116: 154-160.

Doble, B.D. \& Eggers, D.M. 1978. Diel feeding chronology, rate of gastric evacuation, daily ration, and prey selectivity in Lake Washington juvenile sockeye salmon (Oncorhynchus nerka). Transactions of the American Fisheries Society 107: $36-45$.

Dryfoos, R.L. 1965. The life history and ecology of longfin smelt in Lake Washington. Ph.D. dissertation. Seattle, WA: University of Washington.

Edmondson, W.T. 1994. Sixty years of Lake Washington: a curriculum vitae. Lake and Reservoir Management 10: 7584.

Edmondson, W.T. \& Litt, A.H. 1982. Daphnia in Lake Washington. Limnology and Oceanography 27: 272-293.

Eggers, D.M. 1978. Limnetic feeding behavior of juvenile sockeye salmon in Lake Washington and predator avoidance. Limnology and Oceanography 23: 1114-1125.

Eggers, D.M. 1982. Planktivore preference by prey size. Ecology 63: 381-390.

Eggers, D.M., Bartoo, N.W., Rickard, N.A., Nelson, R.E., Wissmar, R.C., Burgner, R.L. \& Devol, A.H. 1978. The Lake Washington ecosystem: the perspective from the fish community production and forage base. Journal of the Fisheries Research Board of Canada 35: 1553-1571.

Enzenhofer, H.J. \& Hume, J.M.B. 1989. Simple closing midwater trawl for small boats. North American Journal of Fisheries Management 9: 372-377.

Faraway, J.J. 2006. Extending the linear model with R. Boca Raton, FL: Chapman \& Hall/CRC.

Gjelland, K.O., Bohn, T., Horne, J.K., Jensvoll, I., Knudsen, F.R. \& Amundsen, P. 2009. Planktivore vertical migration and shoaling under a subarctic light regime. Canadian Journal of Fisheries and Aquatic Sciences 66: 525-539.

Hampton, S.E., Romare, P. \& Seiler, D.E. 2006a. Environmentally controlled Daphnia spring increase with implications for sockeye salmon fry in Lake Washington, USA. Journal of Plankton Research 28: 399-406.

Hampton, S.E., Scheuerell, M.D. \& Schindler, D.E. 2006 b. Coalescence in the Lake Washington story: interaction strengths in a planktonic food web. Limnology and Oceanography 51: 2042-2051.

Hardiman, J.M., Johnson, B.M. \& Martinez, P.J. 2004. Do predators influence the distribution of age-0 kokanee in a Colorado reservoir? Transactions of the American Fisheries Society 133: 1366-1378.

Helser, T.E., Punt, A.E. \& Methot, R.D. 2004. A generalized linear mixed model analysis of a multi-vessel fishery resource survey. Fisheries Research 70: 251-264.

Hoar, W.S. 1954. The behavior of juvenile Pacific salmon, with particular reference to the sockeye (Oncorhynchus nerka). Journal of the Fisheries Research Board of Canada 11: 6997.

Hutchison, M.J. \& Iwata, M. 1997. A comparative analysis of aggression in migratory and non-migratory salmonids. Environmental Biology of Fishes 50: 209-215.
Jensen, O.P., Hrabik, T.R., Martell, S.J.D., Walters, C.J. \& Kitchell, J.F. 2006. Diel vertical migration in the Lake Superior pelagic community. II. Modeling trade-offs at an intermediate trophic level. Canadian Journal of Aquatic and Fishery Sciences 63: 2296-2307.

Johnson, B.M. \& Martinez, P.J. 2000. Trophic economics of lake trout management in reservoirs of differing productivity. North American Journal of Fisheries Management 20: 127-143.

Johnson, J.B. \& Omland, K.S. 2004. Model selection in ecology and evolution. Trends in Ecology and Evolution 19: 101-108.

Jurvelius, J., Leinikki, J., Mamylov, V. \& Pushkin, S. 1996. Stock assessment of pelagic three-spined stickleback (Gasterosteus aculeatus): a simultaneous up- and down-looking echo-sounding study. Fisheries Research 27: 227-241.

Kitano, J., Bolnick, D.I., Beauchamp, D.A., Mazur, M.M., Mori, S., Nakano, T. \& Peichel, C.L. 2008. Reverse evolution of armor plates in threespine stickleback. Current Biology 18: 769-774.

Koehler, M.E., Fresh, K.L., Beauchamp, D.A., Cordell, J.R. \& Simenstad, C.A. 2006. Diet and bioenergetics of lake-rearing juvenile Chinook salmon in Lake Washington. Transactions of the American Fisheries Society 135: 1580-1591.

Lefébure, R., Larsson, S. \& Byström, P. 2011. A temperaturedependent growth model for the three-spined stickleback Gasterosteus aculeatus. Journal of Fish Biology 79:1815-1827.

Levy, D.A. 1987. Review of the ecological significance of diel vertical migrations by juvenile sockeye salmon (Oncorhynchus nerka). Canadian Special Publication of Fisheries and Aquatic Sciences 96: 44-52.

Levy, D.A. 1990. Sensory mechanism and selective advantage for diel vertical migration in juvenile sockeye salmon, Oncorhynchus nerka. Canadian Journal of Fisheries and Aquatic Sciences 47: 1796-1802.

Levy, D.A. 1991. Acoustic analysis of diel vertical migration behavior of Mysis relicta and kokanee (Oncorhynchus nerka) within Okanagan Lake, British Columbia. Canadian Journal of Fisheries and Aquatic Sciences 48: 67-72.

Luecke, C. \& Wurtsbaugh, W.A. 1993. Effects of moonlight and daylight on hydroacoustic estimates of pelagic fish abundance. Transactions of the American Fisheries Society 122: 112-120.

Magnuson, J.J., Crowder, L.B. \& Medvick, P.A. 1979. Temperature as an ecological resource. American Zoologist 19: 331-343.

Maunder, M.N. \& Punt, A.E. 2004. Standardizing catch and effort data: a review of recent approaches. Fisheries Research 70: 141-159.

Mazur, M.M. 2004. Linking visual foraging with temporal prey distributions to model trophic interactions in Lake Washington. Ph.D. dissertation. Seattle, WA: University of Washington.

Mazur, M.M. \& Beauchamp, D.A. 2006. Linking piscivory to spatial-temporal distributions of pelagic prey fishes with a visual foraging model. Journal of Fish Biology 69: 151-175.

Mehner, T., Kasprzak, P. \& Hölker, F. 2007. Exploring ultimate hypotheses to predict diel vertical migrations in coregonid fish. Canadian Journal of Fisheries and Aquatic Sciences 64: 784-786.

Mehner, T., Busch, S., Helland, I.P., Emmrich, M. \& Freyhof, J. 2010. Temperature-related nocturnal vertical segregation of coexisting coregonids. Ecology ofFreshwaterFish 19:408-419. 


\section{Quinn et al.}

Moulton, L.L. 1974. Abundance, growth, and spawning of the longfin smelt in Lake Washington. Transactions of the American Fisheries Society 103: 46-52.

Nowak, G.M. \& Quinn, T.P. 2002. Diel and seasonal patterns of horizontal and vertical movements of telemetered cutthroat trout (Oncorhynchus clarki) in Lake Washington, Washington. Transactions of the American Fisheries Society 131: 452-462.

Nowak, G.M., Tabor, R.A., Warner, E.J., Fresh, K.L. \& Quinn, T.P. 2004. Ontogenetic shifts in habitat and diet of cutthroat trout in Lake Washington, Washington. North American Journal of Fisheries Management 24: 624-635.

Overman, N.C. \& Beauchamp, D.A. 2006. Growth, distribution, and abundance of pelagic fishes in Lake Washington, 2006. Final Report to Seattle Public Utilities. Washington Cooperative Fish and Wildlife Research Unit. Report \# WACFWRU-06-02.

Overman, N.C., Beauchamp, D.A. \& Mazur, M.M. 2006. Growth, distribution, and abundance of pelagic fishes in Lake Washington, 2001-2005. Final Report to Seattle Public Utilities. Washington Cooperative Fish and Wildlife Research Unit. Report \# WACFWRU-06-01.

Piet, G.J. \& Guruge, W.A.H.P. 1997. Diel variation in feeding and vertical distribution of ten co-occurring fish species: consequences for resource partitioning. Environmental Biology of Fishes 50: 293-307.

Quinn, T.P. 2005. The behavior and ecology of Pacific Salmon and trout. Seattle, WA: University of Washington Press.

Quinn, T.P., Kendall, N.W., Rich Jr., H.B. \& Chasco, B.E. 2012. Diel vertical movements, and effects of infection by the cestode Schistocephalus solidus on daytime proximity of three-spined sticklebacks (Gasterosteus aculeatus) to the surface of a large Alaskan lake. Oecologia 168: 43-51.

Robins, J.B., Abrey, C.A., Quinn, T.P. \& Rogers, D.E. 2005. Lacustrine growth of juvenile pink salmon, Oncorhynchus gorbuscha, and a comparison with sympatric sockeye salmon, O. nerka. Journal of Fish Biology 66: 1671-1680.

Scheuerell, M.D. \& Schindler, D.E. 2003. Diel vertical migration by juvenile sockeye salmon: empirical evidence for the antipredation window. Ecology 84: 1713-1720.

Scott, W.B. \& Crossman, E.J. 1973. Freshwater fishes of Canada. Bulletin of the Fisheries Research Board of Canada 184. 966 pages.

Stockwell, J.D., Hrabik, T.R., Jensen, O.P., Yule, D.L. \& Balge, M. 2010. Empirical evaluation of predator-driven diel vertical migration in Lake Superior. Canadian Journal of Fisheries and Aquatic Sciences 67: 473-485.

Stockwell, J.D. \& Johnson, B.M. 1999. Field evaluation of a bioenergetics-based foraging model for kokanee (Oncorhynchus nerka). Canadian Journal of Fisheries and Aquatic Sciences 56(Suppl.): 140-151.

Winder, M. \& Schindler, D.E. 2004. Climate effects on the phenology of lake processes. Global Change Biology 10: 1844-1856.

Winder, M., Schindler, D.E., Essington, T.E. \& Litt, A.H. 2009. Disrupted seasonal clockwork in the population dynamics of a freshwater copepod by climate warming. Limnology and Oceanography 54: 2493-2505.

Wurtsbaugh, W.A. \& Neverman, D. 1988. Postfeeding thermotaxis and daily vertical migration in a larval fish. Nature (London) 333: 846-848. 